\title{
LARGE EUROPEAN SOLAR TELESCOPE (LEST) - \\ A SOLAR TELESCOPE FOR HIGH SPATIAL RESOLUTION AND \\ POLARIMETRIC OBSERVATIONS.
}

\author{
Oddbjørn Engvold \\ Institute of Theoretical Astrophysics \\ University of Oslo, Blindern \\ $\mathrm{N}-0315$ Oslo 3, Norway
}

\section{History}

In 1969 European solar physists formed the Joint Organization for Solar Observation (JOSO). The goals of Joso were to find an ideal site for a large solar instrument, and to create an observatory on this site equipped with a solar telescope for high spatial resolution and polarimetric observations. This instrument is referred to by the acronym LEST which stands for Large European Solar Telescope.

The legal vehicle for this project, the LEST Foundation, was created in 1983. LEST Foundation is domiciled at the Royal Swedish Academy of Sciences, Stockholm, and has presently the following member countries:

$\begin{array}{lll}\text { ITALY } & \text { F.R.G. } & \text { SWEDEN } \\ \text { ISRAEL } & \text { NORWAY } & \text { SWITZERLAND }\end{array}$

Three more countries, AUSTRIA, the NETHERLANDS, and AUSTRALIA may possibly join later this year.

\section{The objectives of LEST}

The following characteristics were formulated by the JOSO Board as the frame of reference for the LEST design (see Zwaan et al., 1982):

- High spatial resolution (close to 0.1 arcsec)

- High photon flux

- Adequate pointing and tracking capabilities for observations of sub-arcsecond solar features for extended periods of time.

Proceedings of the IAU Colloquium No. 79: "Very Large Telescopes, their Instrumentation and Programs", Garching, April 9-12, 1984. 
- Provision for accurate polarimetric measurements, i.e. low instrumental polarization.

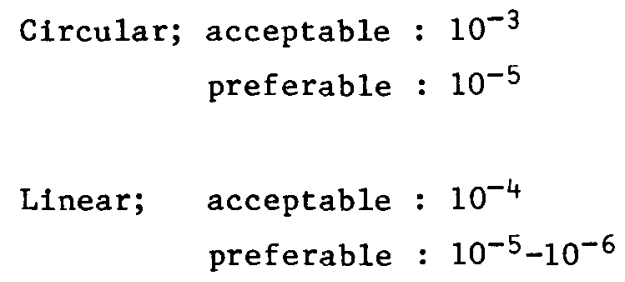

The principal solution for LEST adopted by the LEST Foundation is based on a compact, direct pointing Gregorian or Cassegrain system. The telescope is placed on top of a slender, tall tower. A tertiary mirror is applied to relay the Image to a stationary LEST focus preferably close to the ground.

Details of the mechanical and optical design of LEST is presently being investigated. The results will be published in LEST Foundation Technical Report series.

The principal features which includes recent modifications of the LEST design are described in the following. One will make recommendation and concept selection in the summer 1984 .

\section{THE OPTICAL SYSTEM}

The principal and pointing element of LEST will be a Gregorian telescope with an $\mathrm{f} / 2.4$ primary of diameter close to $2.4 \mathrm{~m}$.

The secondary focus will be located about $2 \mathrm{~m}$ in front of the vertex of the primary mirror. A relay mirror $M_{3}$ forms the final image at the stationary LEST focus.

A flat mirror $\mathrm{M}_{4}$ is located on the optical axis close to the secondary focus. It reflects the beam to the side along the declination axis of the telescope. The fifth mirror $M_{5}$ directs the beam vertically downwards along the azimuth axis to the LEST focus.

A $45^{\circ}$ nearly flat mirror in the primary focus will reflect out of the system most of the energy (5-6 kW). Only a central field of 2-3 arcmin will be admitted through the telescope.

The optical layout is illustrated in Figure 1. 


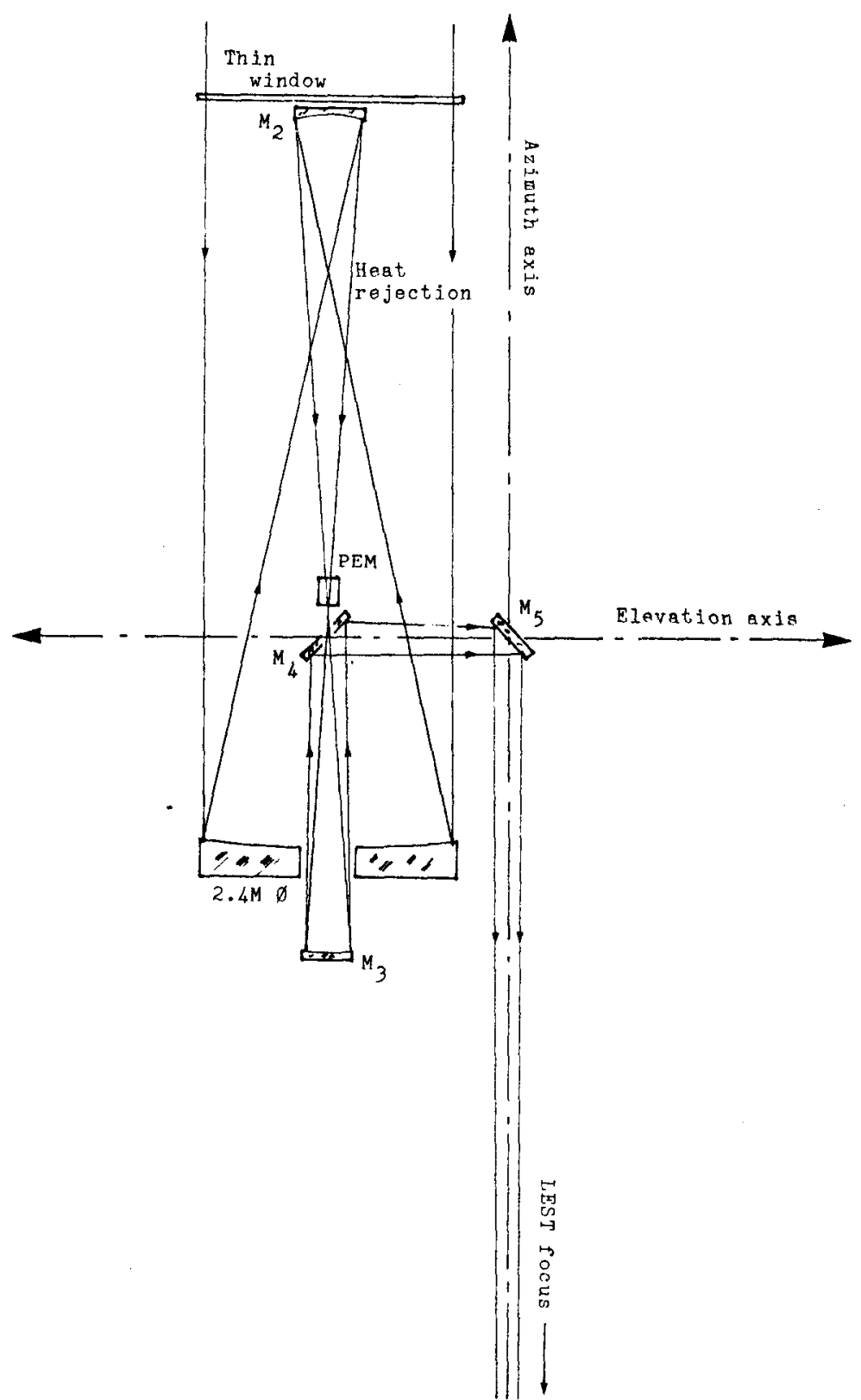

Figure 1. LEST optical layout.

$M_{3}$ also forms an image of the entrance aperture of the telescope close to $M_{5}$ which therefore may serve as an active/adaptive mirror of the system. The tolerances become very small and the mirror positions and alignment must be monitored and actively controlled.

The three-mirror (parabola-ellipsold-ellipsoid) concept gives good imaging capabilities in the LEST focus. The field is diffraction limited to about \pm 9 arcmin. A noticably smaller angular field will be available for observations of the Sun because of radiative heating restrictions. 
THE POLARIZATION MODULATOR

LEST w111 employ piezo-elastic modulators (PEM) rather than $\mathrm{K}^{\star} \mathrm{DP}$ or $\mathrm{A}^{*} \mathrm{DP}$ crystals. PEM's can be placed in divergent 11ght with cone angles as large as $50^{\circ}$ without causing a spread in retardation of more than about $10 \%$. One has devised a scheme which enables all four Stokes parameters to be recorded simultaneously (Stenflo 1984).

The modulator is located in front of the secondary focus (see Figure 1).

\section{THIN ENTRANCE WINDOW AND HELIUM FILLED LIGHT PATH}

In order to avoid using a thick entrance window one plans to fill the entire light path with helium. The helium gas will also help to reduce temperature variations in the thin window and to cool other optical components that are heated by solar radiation (Engvold et a1. 1983).

The thin window for LEST $(1-2 \mathrm{~cm})$ shall preferably be made from fused quartz (Dunn 1984).

\section{THE TELESCOPE MOUNTING}

The mounting will be an alt-azimuth type, which offers a good balance, sturdy and gentle pointing and tracking. Details will be given by Engvold, Andersen and Dunn (1984).

\section{THE TELESCOPE TOWER}

The telescope and mount assembly will be placed on top of a tubular, reenforced, concrete shell tower. With reference to studies of ground based convection at mountain sites one plans to make the tower about 30 meters high. This will place the telescope aperture above most of the strongly disturbed atmosphere near ground.

\section{TWO-STEP TRACKING SYSTEM}

Mechanical vibrations by wind buffeting on the telescope, the tracking of the telescope itself, as well as slow thermally and gravitationally induced 
distortions, will be compensated in real-time. A subsidiary image for tracking will be formed by sections of the primary mirror surface. Limb-guiders will be used at this small solar image in order to provide a good reference for the telescope tracking. The tracking with the massive telescope assembly can be maintained only at a low frequency. The effects of the residual high frequency mechanical vibrations and seeing motions will be monitored in the LEST focus $\left(F_{3}\right)$. The small angular field which is being observed will be stabilized via a closed-1oop system that involves an active mirror $M_{4}$ or $M_{5}$ (Lihe 1984).

\section{The Site for LEST}

A large number of costal sites in the Mediterranian have been inspected as possible candidates for LEST site. One has become increasingly aware of that the best observing condition occurs on sites located on relative small islands in the middle of large oceanic bodies of water under predominantly high pressure atmospheric regions. La Palma and Tenerife of the Canary Islands are two such mountain sites high enough to lie above the cloud inversion layers. Etther place, as well as possibly also Hawalian 1slands, will be explored further as candidate sites for LEST.

\section{References}

Engvold,O., Dunn,R.B., Livingston,W.C., and Smartt,R.N.: 1983, Applied Optics 22,10 .

Engvold,0., Andersen,T., and Dunn,R.B.: 1984, LEST Foundation Technical Report (in preparation)

Dunn,R.B.: 1984, "Window Considerations for LEST", LEST Foundation Technical Report No.3

Lihe,0. von der: 1984, "Adaptive Optical Systems for LEST", LEST Foundation Technical Report No.2

Stenflo,J.-0.: 1984, LEST Foundation Technical Report (In preparation)

Wyller,A.A.: 1983, "LEST - Large European Solar Telescope", EXECUTIVE SUMMARY, The Royal Swedish Academy of Sclences.

Zwaan,C., Deubner,F.L., and Mein,P.: 1982, Joso Annual Report p.20. 